\title{
Correction to: The Prevalence of HIV Among Men Who Have Sex With Men (MSM) and Young MSM in Latin America and the Caribbean: A Systematic Review
}

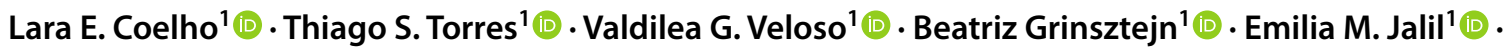 \\ Erin C. Wilson ${ }^{2}(1)$. Willi McFarland ${ }^{2}(1)$
}

Published online: 26 July 2021

๑) Springer Science+Business Media, LLC, part of Springer Nature 2021

\section{Correction to: AIDS and Behavior \\ https://doi.org/10.1007/s10461-021-03180-5}

The original version of this article contained an error. The following text should be included in the Acknowledgment section.

"This study was financed in part by the Coordination for the Improvement of Higher Education Personnel (Coordenação de Aperfeiçoamento de Pessoal de Nível Superior [CAPES]), finance Code 001."
Publisher's Note Springer Nature remains neutral with regard to jurisdictional claims in published maps and institutional affiliations.

The original article can be found online at https://doi.org/10.1007/ s10461-021-03180-5.

Lara E. Coelho

lara.coelho@ini.fiocruz.br

1 Instituto Nacional de Infectologia Evandro Chagas,

Fundação Oswaldo Cruz, INI-Fiocruz. Av. Brasil, 4365

Manguinhos, Rio de Janeiro, RJ, Brazil

2 Department of Public Health, San Francisco, CA, USA 